\title{
The Study of Business English Teaching Based on the Theory of Nida
}

\author{
Lihua Chen ${ }^{1, a^{*}}$
}

${ }^{1}$ Department of foreign languages and affairs, Wuhan city vocational college, Wuhan, 430064, China

meredithshen@163.com

Keywords: Characteristics of business English; Business English; Equivalence.

\begin{abstract}
Functional translation theory translation lively, without limitations, allowing translators for a purpose, the source language text to make necessary adjustments, deletion or even rewrite, but the Style of business English and practical factors, determines the business English translate does not allow free sway, the translator of the original text can make the appropriate adjustments, deletion, but not rewritten. In this case, we should give priority to the Stylistic Features of Business English. Teleology is not a panacea, we can not only by a single theory to guide business English translation, should reference multiple theories. Business English teaching in order to adapt to the requirements of the times, the need for optimization and integration of the teaching philosophy courses. Only by adhering to the dialectical concept of social function and concept of development, the functional translation theory and practice of translation application subject confirm each other in order to better solve practical problems encountered translation problems.
\end{abstract}

\section{Introduction}

With the rapid development of international economy and trade, more and more Chinese goods began to go abroad, business English application along with more and more widely, the role has become increasingly prominent [1,2]. Business English translation teaching, the traditional translation theory, for example, Noida's equivalence theory, cannot meet the needs of business English translation of theory. In this case an urgent need to go beyond traditional translation theory to guide practice teaching business English translation [3]. The functional translation theory provides us with a strong theoretical support. Function to translate this concept in the 1970s by the German scholar, has now developed into a complete system functional translation theory, translation practice has played a real role in guiding significance for the development of translation theory [4-7].

Equivalence Nida is the core of the theory of translation studies, although this theory comes from the translation of the Bible, but to non-literary translation also has some guidance [8]. Equivalence including formal equivalence and functional equivalence, its essence lies in "the original language of the reader's understanding and appreciation of the way language translation of this way of understanding and appreciation of the recipient are compared, it is the realization of communicative language features $[9,10]$.

Functional translation theory from behavioral theory, that the translation is a strong purpose act of translation is based on source language text translation, translation according to the purpose of the target text and source text consistent, so that the cross-cultural exchange to language barriers smoothly. It reflects the translation of purpose, communication and cross-cultural characteristics. Functional translation theory, translation is the highest principle purpose of the law, the highest of any translation strategies are based on the purpose for which the translation. In this regard, Professor Wang Zongyan there had been a clear exposition, pointed out that "the most appropriate role of translation, that is, in the sense that the most appropriate translation." Translation, adjustment of translation, translation and other translation imitation of traditional translation methods do not meet the criteria can be used. Business documents are basically informative text, the main function is to convey information and communication business communication. Functional Translation Theory Translation blindness can be avoided, for teaching business English translation has a strong guiding significance. 


\section{Business English Teaching}

The world economy continues to grow, continue to strengthen the international trend of economic integration, international business activities have become increasingly frequent, investment, foreign trade, technology transfer and other business activities all involve business English. Against this situation, cultivate a knowledge of the language proficiency of Chinese and Western, have extensive international business knowledge and practical skills superb translation of business English translation talents, is the purpose of the current business English translation teaching lies. Business English has a very clear commercial, mass and age characteristics of a particular cultural background and values of great influence on the results of business English communication activities. They face not only simple language conversion. In general, the mere literal effect in Business English is not good. The functional translation theory is that translation is a special form of communication, to achieve the purpose of the translation is more important than rhetoric functional equivalence. Translation process was shown in Fig. 1.

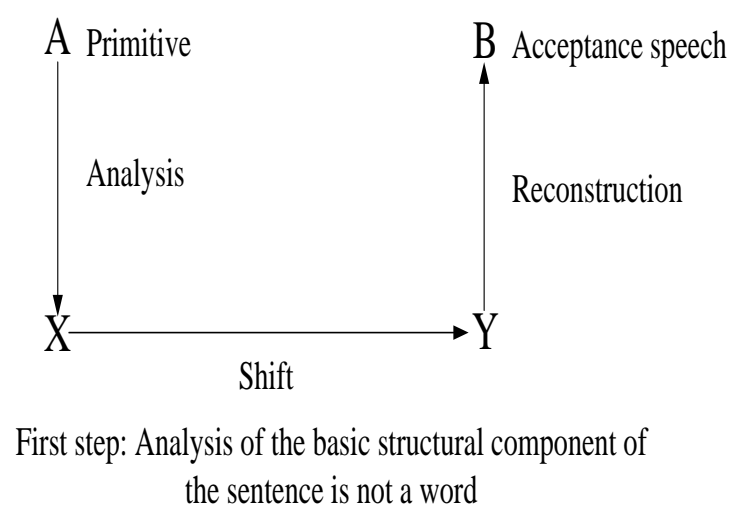

Figure 1. . Translation process

Business English is a unique business and cultural groups, English language way that is a functional variant of modern English, it is different from ordinary English not only in terms of purpose and meaning, but also in the use of words, sentences and chapters build on. Business English more formal style, not for frills, but it cannot develop freely. Even the telephone conversation, the term should be precise, refined. In addition, since business activities are in "profit" for the purpose of the language used have significant communicative purposes.

According to these characteristics of business English, business English translation teaching should implement multi-dimensional, focusing on business English translation of professionalism and practicality; clear business English language features, not rigid follow the traditional translation criteria, should adopt appropriate literal translation, adjustment of translation, translation and other imitation innovative translation methods to achieve the purpose of the translation to the highest standards. The basic structural components of each word in a sentence were shown in Table 1.

Table 1. The basic structural components of each word in a sentence

Facts

\begin{tabular}{cccccccc}
\hline \multicolumn{6}{c}{ Objects Relationship Abstract Activities } & Objects Relationship Abstract Objects Abstract \\
word & Words & Words & words & word & Words & Words & word Words \\
\hline This land & which & \multirow{2}{*}{ once } & barred & The way & of & \multirow{2}{*}{ weary } & travelers now \\
\hline
\end{tabular}

\begin{tabular}{ccccccccc}
\hline \multicolumn{10}{c}{ Objects Relationship Abstract } & Activities & Objects Relationship Abstract & Objects Abstract \\
word & Words & Words & words & word & Words & Words & word & Words \\
\hline a land & for & winter & and & $\begin{array}{l}\text { Summer } \\
\text { vocation }\end{array}$ & a land & of & magic & and \\
\end{tabular}


Business English is a special-purpose English on lexical, syntactic and discourse levels all has their own characteristics. On the lexical level, business English acronyms and technical terms and more multi-use compound words and word pairs, the use of simple phrases expressing characteristics; on the syntactic level, multi-language set of business English, prefer to use declarative sentences and euphemism and other characteristics; in terms of discourse, letters of credit, memos, contracts and business letters and other business language of English style has a fixed format. As a business English for specific and its main aim is to achieve communicative function, that primitive accurately convey information to enable the recipient of the target language text response primitive with the original recipients of this response is consistent.

\section{Functional Translation Theory in Business English Teaching}

Functional translation theory is that, according to the teaching point of view, business English translation can be divided into pragmatic type, culture type or that specific text. From a functional translation theory, the different emphasis in different style, different style: Business Practical translation, should pay attention to some conventions known to say, do as the Romans; advertising business translation, should function and purpose of its persuasive departure; translation of business letters should be courteous and decent, accurate; translation of business contracts, should be accurate and complete, fluent decent. Analysis of various businesses of the text features that will help to use a more appropriate translation strategies in the translation process. However, due to the complexity of the business style, in reality the practice of translation, different business and follow a specific style, conform to the actual situation of translation standards. Functional translation example was shown in Fig. 2.

In international business activities have become increasingly frequent today; business English translation involves not only language, but also related to differences in Chinese and Western cultures. Therefore, in the teaching business English translation, we must understand the importance of Western culture and learning, strengthen import cultural awareness, as much as possible to seek business English knowledge and cultural background and language skills juncture, students with English as a tool, under cross-cultural business environment and carry out trade activities. Students also must enhance learning motivation, not only through books to learn, but also to accumulate experience in practice, through extensive reading and interpersonal experience and use the language policy and apply it to business English translation activities. Must be translated awareness, countries must focus on understanding the cultural background, so in order to avoid cross-cultural communication errors, to promote the smooth cross-cultural business communication.

Business English as a special purpose English itself is constantly incorporating new content diversified open system. Similarly, teaching business English translation also has a multiplex standard, that is, business English translation capability is not a single kind of ability, but by a plurality of abilities, skills composition of the system, its knowledge system is bound with the economic situation, Western language and culture trends and other factors dramatically changed. Therefore, any metaphysical criteria and methods are not feasible. Functional translation theory certainly does not mean that the role of the universal theory. It has the same limitations. 


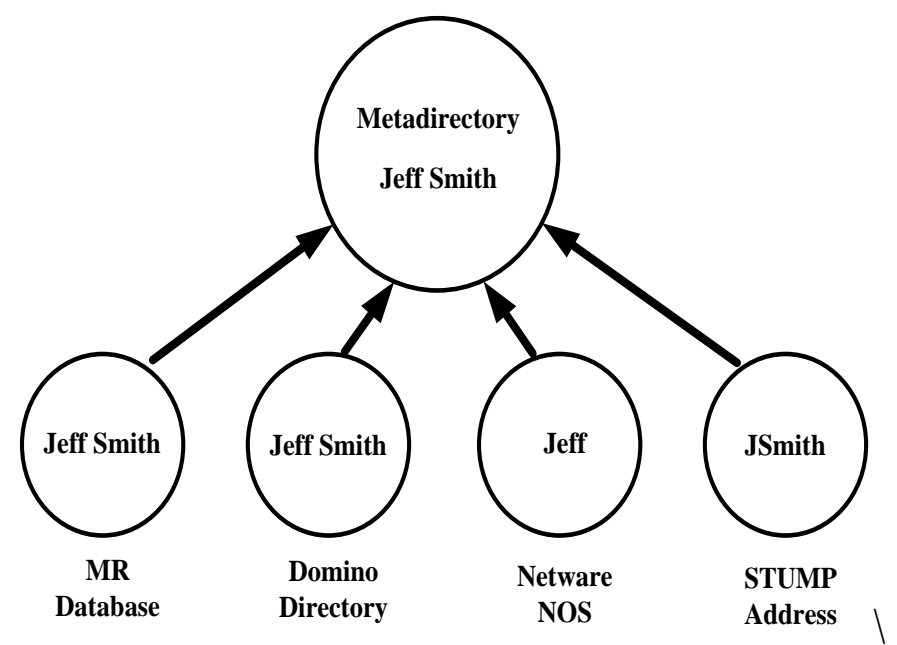

Figure 2. Functional translation example

\section{Conclusions}

Business English teaching itself is closely bound to theoretical and practical courses, not only requires students to master basic translation theory, but also the ability to develop their practical application. To achieve this goal, teaching business English translation must adhere to the functional purpose for the guidelines to complete the real raw material of the source text, the translation of diverse standards applied to a variety of specific business style among. At the same time, but also pay attention to cultivate students' intercultural awareness and improve their business translation capability, cultivate a high-quality business English translators.

\section{References}

[1] Min N. The Application of Functional Translation Theory in Business English Translation [J]. Journal of Liuzhou Teachers College, 2013, 2: 015.

[2] Min N. The Application and Practice of Equivalence Theory in Literary Translation [J]. Overseas English, 2013, 5: 069.

[3] Lei V L C, Zhou I J, He Y. Large-corpus-based Cognitive Study of Translation and Interpreting Processes: Methodological Procedures and Theoretical Implications[J]. 2014.

[4] Juan Z. On Translating Chinese Internet Buzzwords into English from the Perspective of Skopos Theory: Taking the Example of 2012 Chinese Internet Buzzwords [J]. Journal of Hubei Engineering University, 2013, 2: 017.

[5] Chen H. Research on Literary Translation Capability and the Construction of Training Mode[C]//2015 International Conference on Education Technology and Economic Management. Atlantis Press, 2015.

[6] Hao Y. Exploitations of Personal Pronoun Subject in Chinese EFL Majors' Translation: A Case Study of Translation Universals Based on PACCEL-W[J]. Journal of Language Teaching and Research, 2015, 6(3): 669-678.

[7] ZHOU Y, WANG Y. Theoretical basis and strategy selections for the English translation of traditional Chinese medical terms from 1981 to 2010[J]. China Journal of Traditional Chinese Medicine and Pharmacy, 2013, 4: 042. 
[8] Liu H Y, You X F, Wang W Y, et al. The development of computerized adaptive testing with cognitive diagnosis for an English achievement test in China [J]. Journal of Classification, 2013, 30(2): 152 .

[9] Qassem M A, Vijayasarathi G. Problematicity of translating cultural idiomatic expressions from English into Arabic [J]. 2015.

[10]Lu J I N. An Analysis of English Movie Title Translation from the Perspective of Functional Equivalence]. Journal of Jimei University (Philosophy and Social Sciences), 2013, 1: 026. Theory[J 